\title{
Half Load-Cycle Worked Dual SEPIC Single-Stage Inverter
}

\author{
Rong Chen ${ }^{\dagger}$, Jia-Sheng Zhang*, Wei Liu* and Chang-Ming Zheng*
}

\begin{abstract}
The two-stage converter is widely used in traditional DC/AC inverter. It has several disadvantages such as complex topology, large volume and high loss. In order to overcome these shortcomings, a novel half load-cycle worked dual SEPIC single-stage inverter, which is based on the analysis of the relationship between input and output voltages of SEPIC converters operating in the discontinuous conduction mode (DCM), is presented in this paper. The traditional single-stage inverter has remarkable advantages in small and medium power applications, but it can't realize boost DC/AC output directly. Besides one pre-boost DC/DC converter is needed between the DC source and the traditional single-stage inverter. A novel DC/AC inverter without pre-boost DC/DC converter, which is comprised of two SEPIC converters, is studied. The output of dual SEPIC converters is connected with anti-parallel and half load-cycle control is used to realize boost and buck DC/AC output directly and work properly, whatever the DC input voltage is higher or lower than the AC output voltage. The working principle, parameter selection and the control strategy of the inverters are analyzed in this paper. Simulation and experiment results verify the feasibility of the new inverter.
\end{abstract}

Keywords: SEPIC, SPWM, Single-stage inverter, Half load-cycle worked

\section{Introduction}

The two-stage inverter is composed of a high frequency pre-isolated DC/DC converter and a post-grid side inverter $[1,2]$. Restricted by natural conditions, the output power and output voltage of photovoltaic array fluctuate widely. The output voltage of photovoltaic array is generally lower than the peak voltage that occurs at the grid side. Therefore, it is necessary to increase the amplitude of the photovoltaic array output voltage through the boost converter to match the grid voltage $[3,4]$. The addition of a boost converter is necessary, which adds complexity to the system structure, increases the size and weight of inverter and hampers the improvements of system efficiency. In recent years, the single-stage inverter has been widely used in photovoltaic system [5, 6]. Compared with the two-stage grid-connected photovoltaic inverter, the single-stage inverter can reduce the system complexity, save costs and improve reliability.

Two DC/DC converters are needed to implement the dual polarity $\mathrm{DC} / \mathrm{AC}$ voltage because the output voltage of the basic DC/DC converter is unipolar. In recent years, single-stage inverters based on either the dual buck converter or the dual buck-boost converter have been proposed. All inverters are attributed to the combination structure of the DC/DC converter. The single-stage inverter mentioned above can be divided into serial connection and parallel connection [7]. Dual buck-boost inverter [8] and

$\dagger$ 0Corresponding Author: College of Information and Control Engineering, China University of Petroleum (Huadong), China. (chenrongjn@163.com)

* College of Information and Control Engineering, China University of Petroleum (Huadong), China. (zjsycy2003@126.com, \{954476147, 1533569763 \}@qq.com)

Received: November 7, 2014; Accepted: September 25, 2015 flyback inverters $[9,10]$ belong to the serial combination. The input of dual buck-boost inverter is combined in parallel and the output is combined in serial. The output of isolation buck-boost converter used in flyback inverter is also connected in serial and the difference of both the output voltage is AC voltage needed. Because dual DC/ DC converters work simultaneously and an isolation transformer is used in flyback inverter, the circuit loss of single-stage inverter with the output in serial combination is high and it is not conducive to improving conversion efficiency. Dual buck inverter [11, 12] and dual buck-boost inverter [13] belong to the parallel combination. Half loadcycle control is used, where each DC/DC converter only works within a half-cycle and the output of each DC/DC converter is negative or positive, respectively. However, the dual buck inverter works in step-down mode and dual buck-boost inverter suffers from the polarity reversal problem.

SEPIC is one of the six basic DC/DC converters and it has more advantages than the others $[14,15]$. SEPIC has several merits, including the capability of operating in both step-up and step-down modes, its input and output current is continuous, and output voltage is in phase with input voltage without suffering from the polarity reversal problem. These advantages have made SEPIC become a focus of power electronic application in recent years. Dual SEPIC single-stage inverter, which is incomprised of two SEPIC converters and both the output are with anti-parallel connection, is presented in this paper [16, 17]. Half loadcycle control is used in dual SEPIC single-stage inverter, which is based on dual SEPIC. When half load-cycle worked dual SEPIC single-stage inverter works, its operating current is limited to a single SEPIC, which is 
helpful to improve conversion efficiency.

\section{Working Principle of Dual SEPIC Single-stage Inverter}

The main circuit topology of dual SEPIC single-stage inverter is shown in Fig. 1. The dual SEPIC single-stage inverter is comprised of positive unit and negative unit. The positive and negative units are SEPIC converters. The output of positive unit and negative unit are connected in anti-parallel. Switches $S_{1}, S_{2}, S_{3}$ and $S_{4}$ are full-controlled devices. Switches, $S_{1}$ and $S_{2}$, are used in positive unit. $S_{2}$ is used as selection switch of positive unit and $\mathrm{S}_{1}$ is used to control positive half-cycle AC voltage output. Switches, $\mathrm{S}_{3}$ and $\mathrm{S}_{4}$, are used in negative unit. $\mathrm{S}_{4}$ is used as selection switch of negative unit and $\mathrm{S}_{3}$ is used to control negative half-cycle AC voltage output. As shown in Fig. 1, switch $\mathrm{S}_{2}$ is 'on' and the positive SEPIC converter is selected. Switch $\mathrm{S}_{1}$ is controlled by SPWM to achieve positive half-cycle $\mathrm{AC}$ output in the positive half-cycle. During the negative half-cycle, switch $\mathrm{S}_{4}$ is 'on' and the negative SEPIC converter is selected, and switch $\mathrm{S}_{3}$ is also controlled by SPWM to achieve negative half-cycle AC output.

SEPIC converter works in a higher power factor, has no problem of the transformer leakage inductance and changes to the isolation structure easily. These advantages listed above are conducive to improving power factor of dual SEPIC single-stage inverter and promoting its practical application.

To reduce the size and the cost of dual SEPIC singlestage inverter, the two inductors of positive and negative units can be wound on a magnetic core, respectively. In the area of photovoltaic power generation and battery-powered applications, the photovoltaic array and battery can be used as power supply of positive and negative units. Due to its characteristics of step-down and step-up, the output voltage is kept constant by adjusting the duty ratio of driving signal on $\mathrm{S}_{1}$ and $\mathrm{S}_{3}$, under the condition that the supply voltage amplitude difference between positive and negative units is remarkable.

Compared with the other DC/DC converter, the operation mode criterion of SEPIC converter is different and it is determined by the sum of the current through

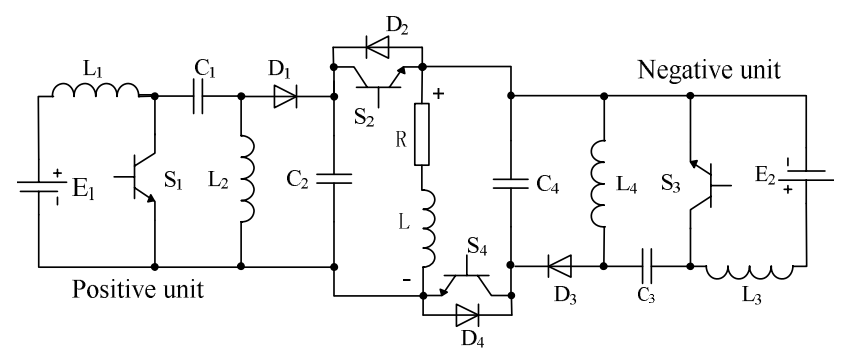

Fig. 1. Main circuit topology of dual SEPIC single-stage inverter

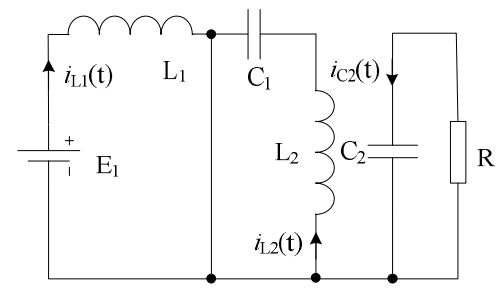

(a)

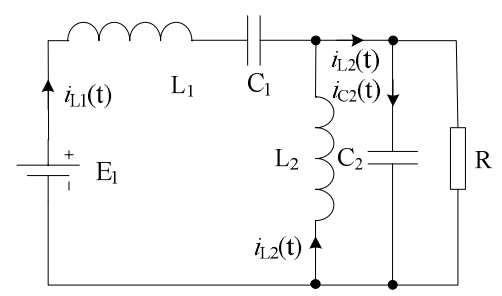

(b)

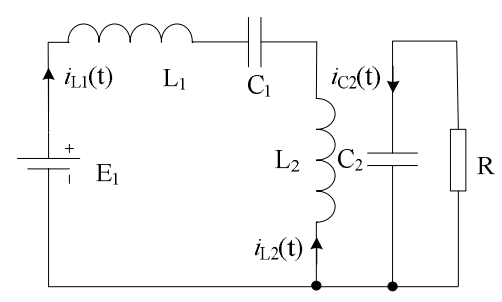

(c)

Fig. 2. DCM operating mode

inductor $\mathrm{L}_{1}$ and $\mathrm{L}_{2}$. If the sum is still greater than zero, SEPIC works in continuous conduction mode (CCM), otherwise, in DCM. The operation mode which works in DCM is needed to achieve AC output voltage. The theoretical analysis is listed below. The working principle of the SEPIC used in positive unit and the negative unit is the same, and the working principle of the positive unit is treated in detail.

The conduction time of switch $\mathrm{S}_{1}$ is $\alpha_{1} T$, discharge time of inductor $\mathrm{L}_{1}$ is $\alpha_{2} T$, and $\mathrm{T}$ is switching period. The operation mode of SEPIC which works in DCM can be divided into three stages.

Stage $1\left[0 \leq t \leq \alpha_{1} T\right]$ : switch $\mathrm{S}_{1}$ is 'on', and diode $\mathrm{D}_{1}$ is 'off'. $E_{1} \rightarrow L_{1} \rightarrow \mathrm{S}_{1}$ and $C_{1} \rightarrow \mathrm{S}_{1} \rightarrow L_{2}$ are the working circuit, respectively. Inductor $\mathrm{L}_{1}$ is charged by the source, $\mathrm{E}_{1}$, and inductor $\mathrm{L}_{2}$ is charged by storage capacitor $\mathrm{C}_{1}$. The operation mode of stage 1 is shown in Fig. 2(a).

Stage $2\left[\alpha_{1} T<t \leq\left(\alpha_{1}+\alpha_{2}\right) T\right]$ : switch $\mathrm{S}_{1}$ is 'off' and diode $\mathrm{D}_{1}$ is 'on'. $E_{1} \rightarrow L_{1} \rightarrow C_{1} \rightarrow D_{1} \rightarrow$ load $\left(C_{2}, R\right.$ and $\left.L\right)$ and $L_{2} \rightarrow D_{1} \rightarrow$ load are the working circuit. During the stage 2, $\mathrm{E}_{1}$ supplys to load and storage capacitor $\mathrm{C}_{1}$. Inductor $\mathrm{L}_{1}$ releases stored energy to the load and also to storage capacitor $\mathrm{C}_{1}$. Storage capacitor $\mathrm{C}_{1}$ releases stored energy to inductor $\mathrm{L}_{2}$. The operation mode of stage 2 is shown in Fig. 2(b).

Stage $3\left[\left(\alpha_{1}+\alpha_{2}\right) T<t \leq T\right]$ : switch $\mathrm{S}_{1}$ is still 'off' and diode $D_{1}$ is 'off'. The sum of the current through the 
inductor $\mathrm{L}_{1}$ and $\mathrm{L}_{2}$ is zero. $E_{1} \rightarrow L_{1} \rightarrow C_{1} \rightarrow L_{2}$ and $C_{2} \rightarrow$ load are the working circuit, respectively. During this stage, $\mathrm{E}_{1}$ supplys to storage capacitor $\mathrm{C}_{1}$ and output capacitor $\mathrm{C}_{2}$ supplys to the load. The operation mode of stage 3 is shown in Fig. 2(c).

\section{Analysis and Parameter Calculation}

The small ripple approximation is used in the steadystate analysis of SEPIC converter. Supposing that the capacity of capacitor $\mathrm{C}_{1}$ and $\mathrm{C}_{2}$ is large enough, though the input voltage $E_{1}$ and output voltage $V$ are constant, respectively. When the SEPIC inverter works in DCM, the voltage across inductor $\mathrm{L}_{1}$ is given by expression (1), and it is in comprised of three expression in a switching period, $T$.

$$
v_{L 1}(t)=\left\{\begin{array}{cc}
E_{1} & \left(0 \leq t \leq \alpha_{1} T\right) \\
-V & \left(\alpha_{1} T \leq t \leq\left(\alpha_{1}+\alpha_{2}\right) T\right) \\
0 & \left(\left(\alpha_{1}+\alpha_{2}\right) T \leq t \leq T\right)
\end{array}\right.
$$

Under the condition that the small ripple approximation is used and by the operating mode listed above, $v_{\mathrm{L} 1}(\mathrm{t})$ is equal to $v_{\mathrm{L} 2}(\mathrm{t})$. Supposing $i_{\mathrm{L}}(\mathrm{t})=i_{\mathrm{L} 1}(\mathrm{t})+i_{\mathrm{L} 2}(\mathrm{t})$ and $d i_{\mathrm{L}}(\mathrm{t}) /$ $d t=v_{\mathrm{L}}(\mathrm{t}) / L$, then the changing rage of $i_{\mathrm{L}}(\mathrm{t})$ is given.

$$
\frac{\mathrm{di}_{\mathrm{L}}(\mathrm{t})}{\mathrm{dt}}=\frac{v_{L 1}(t)}{d t}+\frac{v_{L 2}(t)}{d t}=\frac{L_{1}+L_{2}}{L_{1} L_{2}} v_{L 1}(t)
$$

Substituting expression (1) into expression (2), the changing rate of inductor current of each stage is achieved. Concerning the analysis of operation mode listed above, waveforms of the current through inductor, $\mathrm{i}_{\mathrm{L} 1}$ and $\mathrm{i}_{\mathrm{L} 2}$, and diode, $\mathrm{i}_{\mathrm{D} 1}$, are shown in Fig. 3 .

It can be seen from waveforms of the current through inductor, as shown in Fig. 3, that the peak value of $i_{\mathrm{L}}(\mathrm{t}), i_{\mathrm{pk}}$, is equal to the product of changing rate of $i_{\mathrm{L}}(\mathrm{t})$ and the time during the stage 1 .

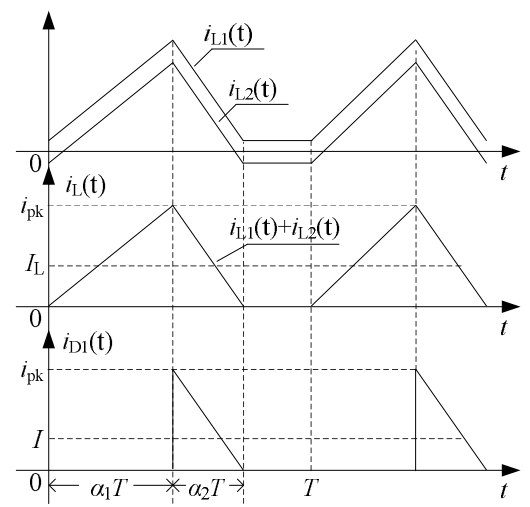

Fig. 3. Waveforms of the current through inductor and diode

$$
i_{p k}=\frac{d i_{L}(t)}{d t} \alpha_{1} T=\frac{L_{1}+L_{2}}{L_{1} L_{2}} E_{1} \alpha_{1} T
$$

According to the principle of inductor volt-second balance, expression (4) is given.

$$
E_{1} \alpha_{1} T-V \alpha_{2} T=0 \Rightarrow \alpha_{2}=\frac{E_{1}}{V} \alpha_{1}
$$

Supposing the current through diode, $\mathrm{D}_{1}$, is $i_{\mathrm{D}}(\mathrm{t})$ and its average value is $\mathrm{I}_{\mathrm{D}}, i_{\mathrm{D}}(\mathrm{t})=i_{\mathrm{C}}(\mathrm{t})+V / R$ by the Kirchhoff's current law. The steady-state average value of capacitor current is zero and average current through $\mathrm{D}_{1}$ is obtained as

$$
I_{D}=\frac{V}{R}
$$

According to the definition of the mean value, the average value of capacitor current is shown in expression (6). Expression (7) is achieved by integration of expression (6), which is equal to the area enclosed by the current. The expression of the average value of the current through diode is given in expression (8).

$$
\begin{gathered}
I_{D}=\frac{1}{T} \int_{0}^{T} i_{D}(t) d t \\
\int_{0}^{T} i_{D}(t) d t=\frac{1}{2} i_{p k} \alpha_{2} T \\
I_{D}=\frac{1}{T}\left(\frac{1}{2} i_{p k} \alpha_{2} T\right)=\frac{1}{2} i_{p k} \alpha_{2}
\end{gathered}
$$

Solving the expression (5) and (8) and substituting expression (3) and (4) into them, expression (9) is achieved.

$$
\frac{V}{R}=\frac{1}{2} \frac{L_{1}+L_{2}}{L_{1} L_{2}} \frac{E_{1}^{2}}{V} \alpha_{1}^{2} T
$$

The voltage conversion ratio is listed as below.

$$
M\left(\alpha_{1}\right)=\frac{V}{E_{1}}=\sqrt{\frac{\left(L_{1}+L_{2}\right) R T}{2 L_{1} L_{2}}} \alpha_{1}
$$

It can be seen from the expression (10), the output voltage of SEPIC, $\mathrm{V}$, is proportional to the PWM pulse duty ratio, $\alpha_{1}$, when the SEPIC inverter works in DCM and in phase with input voltage, $E_{1}$, without suffering from the polarity reversal problem. When the SEPIC inverter works in DCM, the PWM pulse duty ratio, $\alpha 1$, changes in accordance with the sinusoidal and the output voltage, V, changes synchronously.

The steady-state critical condition of CCM and DCM is needed to make the dual SEPIC single-stage inverter work 
in DCM by the selection of the inverter parameters.

When SEPIC works in critical point between CCM and DCM, the current through inductor is in critical state of continuous or discontinuous and SEPIC operates in the first and second stages of DCM. The expression of voltage conversion ratio under CCM is shown in expression (11).

$$
M^{\prime}\left(\alpha_{1}\right)=\frac{\alpha_{1}}{1-\alpha_{1}}
$$

Assuming the average value of current through inductor is $\mathrm{I}_{\mathrm{L}}$, the current through output capacitor, $\mathrm{C}_{2}$, is given.

$$
i_{C 2}(t)=\left\{\begin{array}{cc}
-\frac{V}{R} & \left(0 \leq t \leq \alpha_{1} T\right) \\
I_{L}-\frac{V}{R} & \left(\alpha_{1} T<t \leq T\right)
\end{array}\right.
$$

According to the principle of steady-state capacitor ampere-second balance, expression (13) is achieved.

$$
\int_{0}^{T} i_{C}(t) d t=-\frac{V}{R} \alpha_{1} T+\left(I_{L}-\frac{V}{R}\right)\left(1-\alpha_{1}\right) T=0
$$

Expression (14) is obtained by solving expression (13).

$$
I_{L}=\frac{V}{\left(1-\alpha_{1}\right) R}=\frac{\alpha_{1} E_{1}}{\left(1-\alpha_{1}\right)^{2} R}
$$

As the waveforms of the current through inductor shown in Fig.3, expression (15) is needed to make the inductor current intermittent.

$$
I_{L}<i_{p k} / 2
$$

Substituting expression (3) and expression (14) into expression (15), expression (16) is achieved.

$$
\frac{\alpha_{1} E_{1}}{\left(1-\alpha_{1}\right)^{2} R}<\frac{L_{1}+L_{2}}{2 L_{1} L_{2}} E_{1} \alpha_{1} T
$$

Solving expression (16), expression (17) is given.

$$
\alpha_{1}<1-\sqrt{\frac{2 L_{1} L_{2}}{\left(L_{1}+L_{2}\right) R T}}
$$

Expression (17) is the operation condition of SEPIC working in DCM. Under the condition that the load and circuit parameters are determined and $\alpha_{1}$ meets the expression (17), the SEPIC works in DCM and the output voltage of SEPIC, $\mathrm{V}$, is proportional to $\alpha_{1}$. When the switches $\mathrm{S}_{1}$ and $\mathrm{S}_{3}$ are controlled according to spwm law, $\alpha_{1}$ changes with spwm law and the maximum value of $\alpha_{1}$ is modulation index of spwm, M. As long as $\mathrm{M}<\operatorname{MAX}\left(\alpha_{1}\right)$, AC sinusoidal output voltage is achieved.

To make sure that SEPIC works in DCM within the limitation of modulation index, $\mathrm{M}$, circuit parameters should be selected according to expression (10) and expression (17), and voltage conversion ratio should be considered too.

Load Resistance $\mathrm{R}=10 \Omega$, maxium duty ratio, $\alpha_{1 \max }$, is 0.5 . The voltage conversion ratio $\mathrm{M}(\alpha)>2$, Frequency of triangular 'carrier' wave is $12 \mathrm{kHz}$.

Assuming $\mathrm{L}_{1}=\mathrm{L}_{2}$, according to expression (10) can be obtained that $\mathrm{L}_{1}=\mathrm{L}_{2}<52 \mathrm{uH} . \mathrm{L}_{1}=\mathrm{L}_{2}=40 \mathrm{uH}$ is used and $\mathrm{M}\left(\alpha_{1 \max }\right)=2.28>2$. It is also verified by expression (17) and the maxium duty ratio $\alpha_{1 \max }=0.5<0.78$.

$\mathrm{E}_{1}=\mathrm{E}_{2}=24 \mathrm{~V}$. Maxium peak voltage is $54 \mathrm{~V}$ and $\mathrm{rms}$ voltage, $\mathrm{V}_{\mathrm{o}}$, is $38 \mathrm{~V}$. The output capacitor is used to filter out high-order harmonic component. The greater the output capacitor, the better the filter and the larger the current through the output capacitor $\mathrm{C}_{2}[18]$. Generally, current through output capacitor is less than $50 \% \mathrm{I}_{\mathrm{o}}$.

According to expression (18),

$$
I_{C 2}=C_{2} \frac{d v_{o}}{d t} \Rightarrow C 2 \leq \frac{I_{C 2}}{V_{o} \omega_{o}}=\frac{1.9}{38 * 50 * 2 \pi}
$$

The output capacitor is obtained, $\mathrm{C}_{2}<159 \mathrm{uF}$ and $\mathrm{C}_{2}=40$ $\mathrm{uF}$ is used.

Storage capacitor $C_{1}$ is used for energy storage and release. During the period of the switch is 'on', the fluctuation voltage across $\mathrm{C}_{1}$ is

$$
\Delta V_{C 1}=\sqrt{\frac{\left(L_{1}+L_{2}\right) R T_{s}}{2 L_{1} L_{2}}} \cdot \frac{V_{C 1} \alpha_{1}^{2} T_{s}}{C_{1} R}
$$

Supposing that $\Delta \mathrm{V}_{\mathrm{C} 1} / \mathrm{V}_{\mathrm{C} 1}<0.1, \alpha_{1 \max }$ is 0.5 and $\mathrm{C}_{1}$ is obtained as $\mathrm{C}_{1}>8.33 \mathrm{uF} . \mathrm{C}_{1}=20 \mathrm{uF}$ is used.

\section{Control Scheme of Dual SEPIC Single-stage Inverter}

In order to ensure that the output voltage of the dual SEPIC single-stage inverter is sinusoidal, the system control scheme in Fig. 4 is used. Half load-cycle control is used to ensure positive and negative unit work alternately. Switches $S_{1}$ and $S_{3}$ work according to unipolar SPWM law, and the driving signal of $\mathrm{S}_{1}$ is achieved by comparing

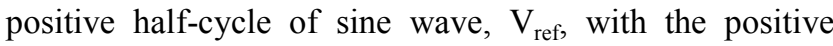
triangular 'carrier' wave, and the driving signal of $\mathrm{S}_{3}$ is achieved by comparing reversal negative half-cycle of sine wave, $\mathrm{V}_{\text {ref, }}$, with the positive triangular 'carrier' wave. $\mathrm{S}_{2}$ and $\mathrm{S}_{4}$ work alternately, $\mathrm{S}_{2}$ is 'on' in positive half-cycle and $\mathrm{S}_{4}$ is 'on' in negative half-cycle. The dead-band delay 


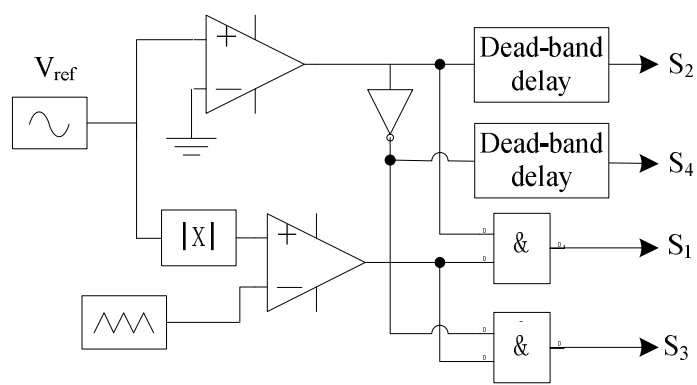

Fig. 4. the system control scheme

between $\mathrm{S}_{2}$ and $\mathrm{S}_{4}$ is needed to prevent shoot-through between the two output capacitors $\mathrm{C}_{2}$ and $\mathrm{C}_{4}$. The output voltage of positive half-cycle and output voltage of negative half-cycle are contrlled by positive unit and negative unit, respectively.

It should be noted that when the unipolar SPWM is used, modulation ratio, $M$, should be limited to ensure positive/negative unit of inverter work in DCM. Once the converter works in CCM, the inverter does not work properly according to the sine law which causes the output voltage to distort.

\section{Simulation Results based on PSIM}

In this paper, simulation model of dual SEPIC singlestage inverter is built using PSIM. The simulation parameters are listed as below. DC source $E_{1}=E_{2}=24 \mathrm{~V}$. Storage capacitor $\mathrm{C}_{1}=\mathrm{C}_{3}=20 \mu \mathrm{F}$ and output capacitor $\mathrm{C}_{2}=\mathrm{C}_{4}=40 \mu \mathrm{F}$. Inductor, $\mathrm{L}_{1}=\mathrm{L}_{2}=\mathrm{L}_{3}=\mathrm{L}_{4}=40 \mu \mathrm{H}$. Resistive load is used, load resistance $\mathrm{R}=10 \Omega$. Frequency of triangular 'carrier' is $12 \mathrm{kHz}$. Frequency of sinusoidal reference waveform is $50 \mathrm{~Hz}$. Modulation index is 0.5 and MOSFET is used.

According to expression (17), when $\alpha 1 \in[0,0.78]$, the inverter works in DCM and modulation index $\mathrm{M}=0.5$ is included.

The simulation results are shown in Fig. 5. Fig. 5(a) and Fig. 5(b) show current through inductor, $\mathrm{i}_{\mathrm{L} 1}$ and $\mathrm{i}_{\mathrm{L} 2}$, and current through diode, $\mathrm{i}_{\mathrm{D} 1}$. It can be observed from Fig. 5(a) and Fig. 5(b) that current through inductor is consistent with the theoretical analysis. Fig. 5(b) also demonstrates the DCM operating mode. Fig. 5(c) shows current through inductor, $\mathrm{i}_{\mathrm{L} 1}$ and $\mathrm{i}_{\mathrm{L} 2}$, and output voltage of inverter, $\mathrm{v}_{\mathrm{o}}$. Fig. 5(d) shows voltage across storage capacitor, $\mathrm{v}_{\mathrm{C} 1}$ and output capacitor, $\mathrm{v}_{\mathrm{C} 2}$, and output voltage of inverter, $\mathrm{v}_{\mathrm{o}}$. It is clear from Fig. 5(c) and Fig. 5(d) that the two SEPIC converter work in alternate half load-cycle worked as studied in this paper and operate in both step-up and step-down modes. In a word, the simulation results reveal that a single-stage boost inverter can be achieved by using dual SEPIC singlestage inverter and shows a good agreement with the analysis above.

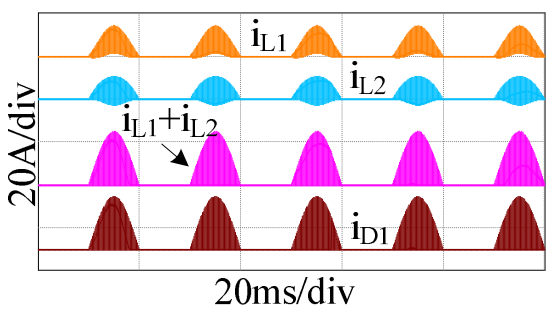

(a)

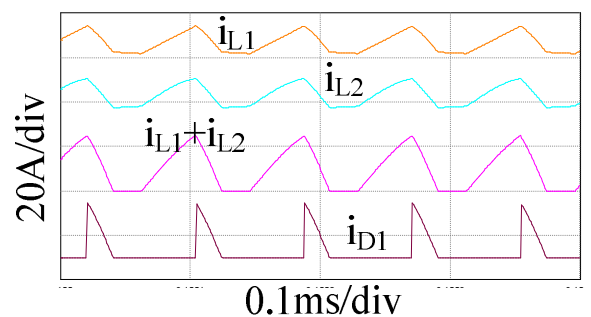

(b)

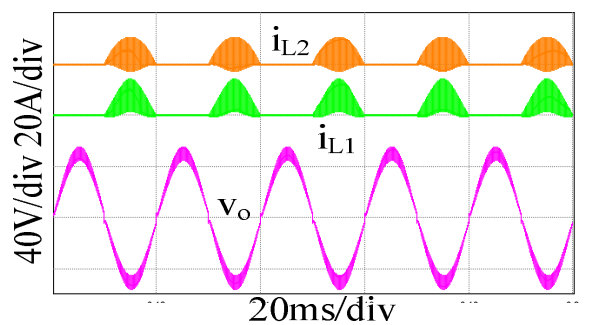

(c)

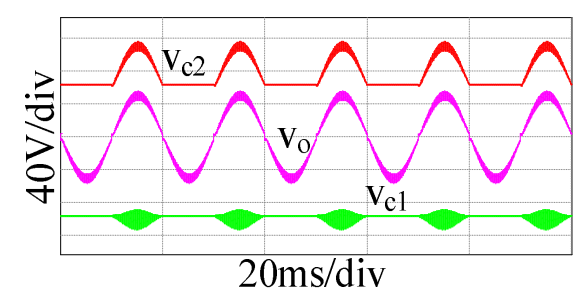

(d)

Fig. 5. Simulation result

\section{Experiment Results}

A prototype is implemented to validate the feasibility of the dual SEPIC single-stage inverter. The TMS320F2812 digital signal controller is used for control strategy. The circuit parameters are consistent with the simulation parameters.

MOSFET IRF740 and fast recovery diode MUR8100E series combination are used as unidirectional switch $S_{1}$ and $S_{3}$ to meet with the input voltage of $24 \mathrm{~V}$. Switch $S_{2}$ and switch $\mathrm{S}_{4}$ are MOSFET IRF740. A digital storage oscilloscope is used to record experiment waveform. The experiment results of dual SEPIC single-stage inverter with resistive load are depicted in Fig. 6. Current through inductor, $\mathrm{i}_{\mathrm{L} 1}$ and $\mathrm{i}_{\mathrm{L} 2}$ and diode, $\mathrm{i}_{\mathrm{D} 1}$, are shown in Fig. $6(a)$. The waveforms of current through inductor $\left(i_{\mathrm{L} 1}\right.$ and 
$\mathrm{i}_{\mathrm{L} 2}$ ) and diode $\left(\mathrm{i}_{\mathrm{D} 1}\right)$ during a few switching periods are depicted in Fig. 6(b), which correctly demonstrates the DCM operating mode. Fig. 6(c) depicts current through inductor, $i_{L_{1}}$ and $i_{L 2}$, and output voltage of inverter, $v_{0}$. Fig. 6(d) shows voltage across storage capacitor, $\mathrm{v}_{\mathrm{Cl}}$, and output capacitor, $\mathrm{v}_{\mathrm{C} 2}$, and output voltage of inverter, $\mathrm{v}_{\mathrm{o}}$. It is evident from Fig. 6(c) and Fig. 6(d) that half load-cycle worked dual SEPIC single-stage inverter works properly and the predicted $\mathrm{AC}$ voltage output is obtained. A very good agreement can be seen between simulation and experimental results.

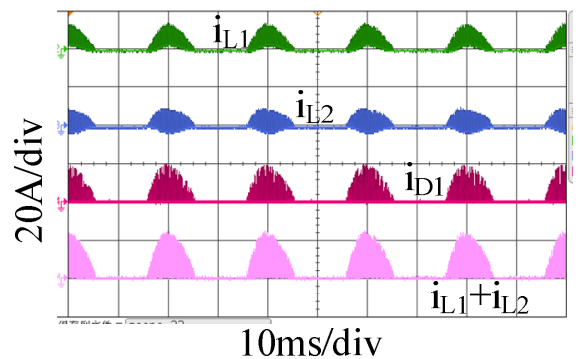

(a)

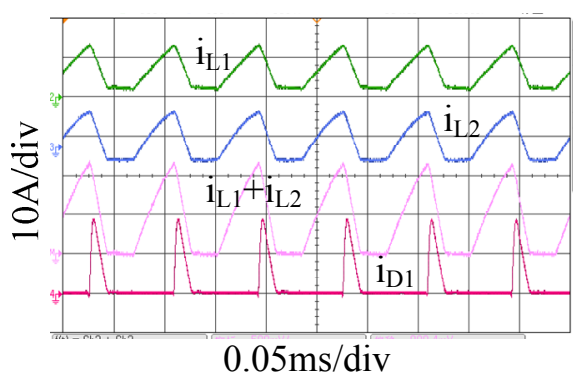

(b)

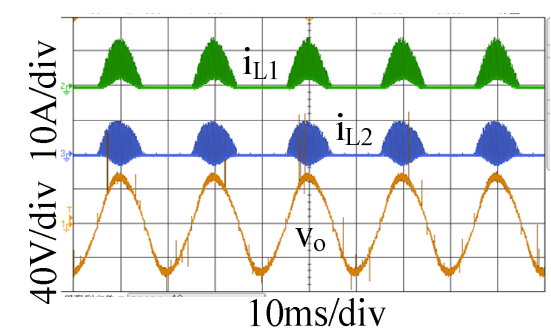

(c)

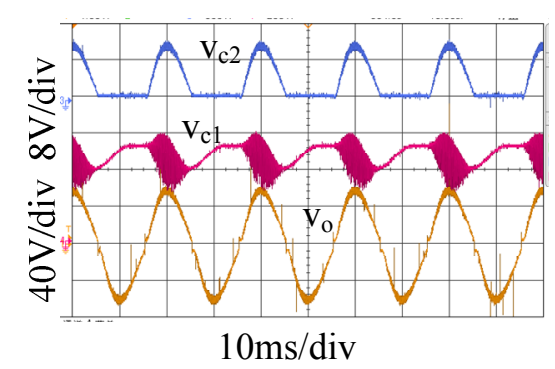

(d)

Fig. 6. Experiment results

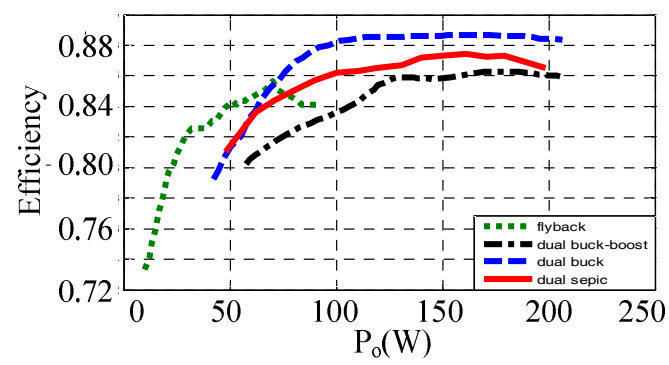

Fig. 7. Efficiency curve of single-stage inverter

The efficiency curve of dual buck inverter [12], dual SEPIC inverter, dual buck-boost inverter [13], and flyback inverter [10] are shown in Fig. 7. It can be found that the efficiency of dual buck inverter is the highest. However, compared with both dual SEPIC inverter and dual buckboost inverter, dual buck inverter only operates in step down mode, hence limiting the flexibility of the output voltage. On the other hand, the efficiency of flyback inverter is the lowest. It is caused by isolation transformer used in flyback inverter and full load-cycle operating mode of flyback inverters. Although the efficiency of both dual SEPIC inverters and dual buck-boost inverter is lower than that of dual buck inverter, these two kinds of inverters can operate in step-up and step-down modes, and alternately half load-cycle. Moreover, it can be found from Fig.7 that the efficiency of dual SEPIC inverter is higher than that of dual buck-boost inverter. It should be noted that the dual SEPIC inverter eliminate the polarity reversal problem which exists in dual buck-boost inverter.

\section{Conclusion}

A novel dual SEPIC single-stage inverter has been presented and analyzed. The proposed single-stage inverter is derived from the relationship between the input voltage and output voltage of SEPIC converter which operates in DCM. The output of both SEPIC is connected with antiparallel. The half load-cycle control is used successfully in dual SEPIC single-stage inverter. The AC output voltage is good. Simulation model of dual SEPIC singlestage inverter using PSIM was established. Finally, a prototype of the inverter using TMS320F2812 was developed. The experimental and simulation results verify the feasibility of the inverter and the correctness of theoretical analysis.

\section{Acknowledgements}

This work was supported by Science and Technology Development Program of Shandong Province (No.2013 GSF11607) and the Fundamental Research Funds for the Central Universities of China (No.13CX06090A). 


\section{References}

[1] B. A. Mcdonald, and E. L. Price, "High efficiency two stage inverter," U.S. Patent 7218541,B2, May.15, 2007.

[2] Z. M. Ye, P. K. Jain, and P. C. Sen, "Two stage resonant inverter for AC distributed power supply," in Annu. IECON, pp. 239-244, 2004.

[3] M.E.S. Ahmed, M. Orabi, and O.M. AbdelRahim, "Two-stage micro-grid inverter with high-voltage gain for photovoltaic applications," IET Power Electronics, Vol. 6, No. 9, pp. 1812-1821, Sep, 2013.

[4] H. S. Bae, J. H. Park, and B. H. Cho, "New MPPT Control Strategy for Two-Stage Grid-Connected Photovoltaic Power Conditioning System," Journal of Power Electronics, Vol. 7, No. 2, pp. 174-180, April, 2007.

[5] T. Kerekes, R. Teodorescu, and P. Rodríguez, "A new high-efficiency single-phase transformerless PV inverter topology," IEEE Trans. Industrial Electronics, Vol. 58, No. 1, pp. 184-191, Jan, 2011.

[6] E. S. Sreeraj, C. Kishore, and B. Santanu, "Onecycle-controlled single-stage single-phase voltagesensorless grid-connected PV system," IEEE Trans. Industrial Electronics, Vol. 60, No. 3, pp. 1216-1224, Mar, 2013.

[7] Y. D. Ma, B. Qiu, and Q. Cong, "Research on singlestage inverter based on bi-directional Buck DC converter," in Proc. ISPE, pp. 299-303, 2010.

[8] J. Matas, L. G. Vicuna, and J. M. Guerrero, "A discrete sliding mode control of a buck-boost inverter," in Proc. PESC, pp. 140-145, 2002.

[9] Y. C. Liang, L. Sun, and C. Y. Gong, "Research on flyback inverter," in Proc. CSEE, pp. 85-89, 2005.

[10] C. Y. Gong, S. Lin, and Y. C Liang, "Research on the control strategies of single-stage flyback inverter," in PESC'06. 37th IEEE, pp. 1-5, 2006.

[11] F. Hong, R. Z. Shan, and H. Z. Wang, "A novel dual buck inverter with integrated magnetics," Transactions of China Electrotechnical Society, Vol. 22, No. 6, pp. 76-81, Jun. 2007.

[12] J. Liu and Y. G. Yang, "A novel hysteresis current controlled dual buck half bridge inverter," in PESC'03. 2003 IEEE 34th Annual, pp. 1615-1620, 2003.

[13] B. J. Ji, and F. Hong, "Half load-cycle worked dual buck-boost single-stage inverter," Transactions of China Electrotechnical Society, Vol. 26, No. 11, pp. 53-60, Nov. 2011.

[14] J. Chen and C. Chang, "Analysis and Design of SEPIC Converter in Boundary Conduction Mode for Universal-line Power Factor Correction Applications," in Proc. PESC, pp. 742-747, 2001.

[15] J. Hu, A. D. Sagneri, and J. M. Rivas, "High-frequency resonant SEPIC converter with wide input and output voltage ranges," IEEE Trans. Power Electronics, Vol. 27, No. 1, pp. 189-200, Jan, 2012.
[16] Y. M. Chen, Y. C. Liu, and S. H. Lin, "Double-input PWM dc-dc converter for high/low voltage sources," IEEE Trans. Industry Electronics, Vol. 53, No. 5, pp. 1538-1544, Oct. 2006.

[17] Y. Li, X. B. Ruan, and D. S. Yang, "Synthesis of multiple-input dc/dc converters," IEEE Trans. Power Electronics, Vol. 25, No. 9, pp. 2372-2385, Sep. 2010.

[18] E. Babaei and M. E. Mahmoodieh, "Calculation of output voltage ripple and design considerations of Sepic converter," IEEE Trans. Industry Electronics, Vol. 61, No. 3, pp. 1213-1222, Mar. 2014.

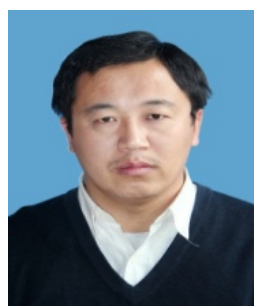

Rong Chen He received his B. S. and M. S. degree from Shandong University of Science and Technology. China. He is working toward his $\mathrm{Ph}$. D from China University of Petroleum (Huadong). His research interests include electric machine drives, power electronics, highfrequency soft switching converters, and power factor correction.

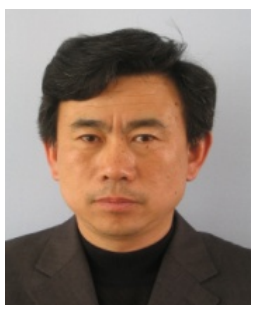

Jia-ShengZhang He received his M. S. and $\mathrm{Ph}$. D. from Beijing Jiaotong University, China. His research interests include power electronics, motor drives, power quality control, renewable distributed power sources, and digitalsignal-processor-based control of power converters.

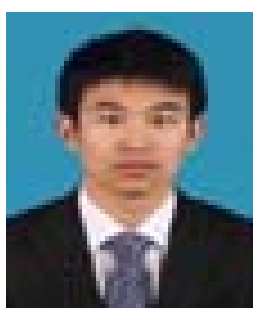

Wei Liu He received the M. S from China University of Petroleum (Huadong), China. He is working toward his M. S from China University of Petroleum(Huadong). His research interests include high-frequency inverters soft switching, inverter modeling, and nonlinear control techniques.

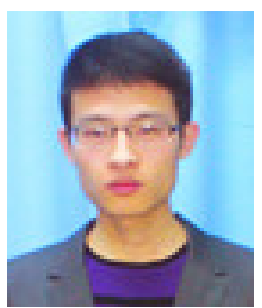

Chang-Ming Zheng He received the M.S from China University of Petroleum (Huadong), China. He is working toward his MS from China University of Petroleum(Huadong). His research interests include high-frequency inverters, and motor control techniques. 